\title{
Una mirada a la antropología laboral desde la economía
}

\author{
Velandia Díaz, D. (2019). Imprentas en la era neoliberal. \\ Biografía colectiva del trabajo en las artes gráficas en \\ Bogotá. Universidad Nacional de Colombia. 380 p.
}

\section{Camilo Guzmán Coronado ${ }^{1}$ \\ Universidad Nacional de Colombia \\ (D) https://orcid.org/0000-0002-6328-0420}

En Imprentas en la era neoliberal, Daniel Velandia Díaz profundiza en la dinámica de una actividad económica desde una perspectiva local y de forma particular. Este libro coloca como foco de análisis la industria de las artes gráficas en Bogotá y su proceso de transformación a finales del siglo XX y comienzos del siglo XXI. El autor muestra como la nueva estructura impuesta desencadenó nuevas relaciones laborales, demanda de capacidades, conocimientos y tecnología; estas relaciones marcaron esta actividad, así mismo evidenciaron algunas "fallas" de mercado, tales como la ausencia de regulación y competencia desleal, entre otros. Por otra parte, el autor analiza, a partir de la experiencia directa de los involucrados en diferentes roles del sector, las dinámicas jerárquicas en el que hacer laboral, los roles de género, el "aprender haciendo", entre otras dimensiones que describen a esta industria desde el pasado siglo.

Desde un enfoque etnográfico, el autor se introduce y profundiza en la comunidad que constituye el sector de las artes gráficas en Bogotá, consolidó una base de información que aterrizó en una biografía colectiva sobre las diferentes dimensiones de la actividad (producción, comercialización, condiciones laborales, relaciones sociales, etc.). Velandia Díaz utilizó, para ello, su conocimiento previo de la actividad, gracias a la presentación de su vida laboral familiar y a la realización directa de la actividad propia como medio de sustento, en su juventud. El autor implementa instrumentos que permiten diagnosticar, analizar y conectar los diferentes relatos de la comunidad para crear esta biografía de las artes gráficas en Bogotá, donde los conceptos de colectividad, brechas de género, aglomeración o concentración productiva y, finalmente: subjetividad, se desprenden de una forma estrecha de las relaciones patrimoniales en la producción.

Los conceptos son contextualizados desde las experiencias de los sujetos de estudio, donde la colectividad se presenta como la red constituida por los trabajadores del sector, donde el intercambio de conocimientos y la contratación directa o indirecta son el principio de la constitución de esta red. Los contextos son presentados en las diferentes etapas productivas, así como en los diferentes momentos en el tiempo propio de los roles, jerarquías y relaciones que se constituían. Vale la pena destacar que se resalta cómo las brechas de género se hacían presentes, se asignaban, antes y ahora, roles específicos a las mujeres: a este grupo de población se le limita a unas actividades específicas.

\footnotetext{
${ }^{1}$ Correo electrónico: cguzmanco@gmail.com
} 
De la misma forma, gracias a la construcción de una red en la comunidad asociada a esta actividad, la concentración de los diferentes servicios de esta industria en lugares específicos de la ciudad constituyó zonas geográficas donde se localizan principalmente. Dentro de las dinámicas que se desencadenaron por la llegada del neoliberalismo, se observó un crecimiento de las pequeñas y medianas empresas en el sector, el autor expone un concepto que es pertinente para describir este fenómeno o consecuencia de las condiciones y relaciones que se establecieron en la era neoliberal y es la subjetividad empresarial. Para los trabajadores y trabajadoras surge el nuevo objetivo de "la independencia". Esta es el símbolo de mejora económica y social, donde el concepto de relaciones patrimoniales se hace presente, siendo el rol de patrón (además de una posición de poder dentro de la estructura económica y social de una organización) la representación de un progreso social significativo y la materialización del proceso acumulativo y de capitalización que caracteriza el proyecto neoliberal impuesto.

Uno de los aspectos que se rescatan principalmente en este libro, es la forma en que la antropología laboral aborda los procesos históricos y sociales que se dieron en la construcción de sectores productivos a nivel local. Este enfoque tiene en cuenta las experiencias de los directamente involucrados, ya sea como parte de la fuerza laboral directa o de intermediarios de los bienes y servicios ofertados, esto le permite al autor encontrar un diagnóstico claro y los momentos cuando hubo cambios estructurales en el sector que transformaron el quehacer de la actividad.

La ciencia económica aborda las dinámicas de productores desde un enfoque en el que se modelan los beneficios, costos y variables que son objeto y que están involucradas en el proceso productivo con el fin de tener indicios sobre las decisiones que se toman en el mercado, la definición de precios y, las decisiones de los agentes en el mercado. La economía, entonces, parte del principio de racionalidad en búsqueda del beneficio. De forma propositiva, en el libro hay una perspectiva más amplia puesto que el análisis se relaciona con otros factores que el autor expone, tales como las relaciones laborales y la introducción de tecnología. Esta última, aunque generaba presiones sobre los pequeños y medianos productores para obtener maquinaria y equipos de vanguardia, también permitió percibir beneficios directos en relación con los volúmenes de producción.

De la misma forma, el autor muestra que la tecnología tiene en cuenta modelos micro y macro, ya que la introducción o generación de tecnología impacta directamente los rendimientos de los factores productivos, puede reducir costos, entre otros beneficios. Sin embargo, a través de las memorias de los trabajadores del sector de las artes gráficas, las presiones por la obtención de tecnología pueden significar el cierre de negocios, por lo tanto, pérdida de empleos. En el mismo sentido, la ciencia económica también contempla estos efectos, dado que existen barreras económicas que pueden interferir en el acceso a tecnología, reduciendo competitividad y llevando, con el paso del tiempo, a cierres definitivos de unidades productivas.

Por otro lado, el autor muestra los procesos sociales que se fueron consolidando en aglomeraciones y/o concentraciones productivas en la ciudad, donde ex compañeros de trabajo, amigos y colegas, que se formaron en la actividad diaria, se reunieron (de forma deliberada o incidental) para dar lugar al establecimiento de zonas específicas para las artes gráficas. En economía el establecimiento de zonas productivas también ha sido objeto de estudio. La geografía económica estableció los primeros análisis formales en la concentración de sectores productivos, así como los encadenamientos que traía consigo. 
Aunque, desde una perspectiva meramente económica la ubicación espacial de sectores productivos responde a la ubicación estratégica de las industrias, comercios o servicios con respecto al consumidor final, infraestructura o proximidad con los recursos que son parte del proceso productivo.

Aquí, el autor expone el proceso histórico de la ubicación de la industria. Este proceso también responde a la cercanía con la clientela frecuente (consumidor), pero además, a la ubicación de ciertas zonas que estaban tradicionalmente referenciadas como centros de trabajo del sector. De esta forma, a partir de la percepción de la comunidad en general, muchas zonas se expandieron en razón de mantener el mercado, así como nuevos empresarios e independientes en las artes gráficas se ubicaron allí, puesto que buscaron aprovechar las ventajas que ofrecían estas concentraciones.

Las actividades económicas son parte de las dinámicas de la sociedad, no solo en un sentido estricto como bases de producción de bienes y servicios, o como las fuentes de generación de ingreso para los hogares, sino que son un sistema de relaciones e intercambios constantes (conocimiento, tecnología, etc.) en la sociedad actual. En la ciencia económica, estas relaciones se abordan entre las empresas (firmas) y hogares (agentes) desde la microeconomía. Se estudian aspectos tales como la maximización de beneficios de los agentes con los ingresos percibidos y la maximización de utilidades, minimización de costos, entre otros aspectos relevantes en esta dinámica. Sin embargo, variables como la transferencia de conocimientos a partir de la colectividad y experiencia inmersos en el flujo económico diario, son variables que se modelan y analizan en agregados y no se profundiza en detalle como lo pueden abordar otras disciplinas. La antropología y, específicamente el enfoque laboral de esta disciplina, muestra que a partir de una metodología propia es posible profundizar en las relaciones y las transiciones que soportan las construcciones sociales y laborales en la sociedad.

El primer capítulo aborda los saberes de la industria de las artes gráficas, expone los roles y detalles técnicos de la actividad, se aproxima a cada etapa de producción y, a las dinámicas que se presentaban en esta industria. Este capítulo contextualiza y le brinda al lector conceptos puntuales; en el trasfondo señala las diferentes tensiones y relaciones que se vivían en los centros de producción, muestra cómo la introducción de tecnología enfrentaba a los trabajadores a retos para no rezagarse y ser competitivos en el mercado. Durante el periodo estudiado, siempre primó el aprender haciendo, teniendo en cuenta la falta de capacitación y conocimientos formales en la actividad y, el contacto con las herramientas que conformaban el principal medio de trabajo. De esta forma, la "capacidad" de las personas fue entonces, y es ahora, el factor decisivo para sobrevivir en la industria; esta capacidad, además, es un valor agregado indirecto dentro de una empresa, implica la posibilidad de ascenso en una jerarquía implícita (en muchas ocasiones, de acuerdo con los conocimientos en maquinaria se determina el salario de las personas).

El capítulo, además, expone las tensiones de género. Señala que hubo un contexto social en el cual a los hombres se les enseñaba y a las mujeres no. Las mujeres aprendían de forma indirecta ciertos oficios, inclusive con el conocimiento necesario para ciertas actividades, a ellas se les relegaba a tareas que implicaran menor fuerza física. Otro aspecto para rescatar de este primer capítulo es el detrimento del arte gráfico con el arribo de tecnología de la mano de los computadores. A medida que creció el acceso a los computadores por parte del público no especializado o sin experiencia en el sector, los 
clientes pudieron explorar el diseño y, por la misma razón, menospreciar el valor de este y de las personas que llevaban en la actividad varios años. Muchas veces el esfuerzo, la técnica y el conocimiento de los artistas gráficos fue minimizado. Además, se presentaron nuevas tensiones entre quienes recibían formación académica en el arte gráfico y los empíricos del sector, sin embargo, la tensión mayor se representó en la resistencia conjunta de las artes gráficas a las dinámicas desencadenadas por el neoliberalismo.

En el segundo capítulo se desarrolla un tema central de toda actividad económica: el mercado laboral. El autor expone, desde la subjetividad, el deterioro de las condiciones de trabajo y la reducción de la ocupación de la mano de obra en el sector; estos fenómenos tuvieron consecuencias en el bienestar de las personas. El deterioro de las condiciones laborales comienza a ser un problema colectivo que lleva a un deterioro del estado de bienestar en general. Este capítulo muestra cómo esta situación puede ser generalizada puesto que, no es ajena a los demás sectores que componen la economía. Bien sabemos que las prácticas empresariales se emulan con facilidad. Los empleadores percibieron como contradictorios los derechos de los trabajadores y las necesidades del negocio; así mismo, el sistema en su conjunto flexibilizó ciertas reglas en este juego, lo que permitió a los empleadores vulnerar la estabilidad laboral.

Por otra parte, el capítulo presenta cómo las relaciones entre los trabajadores y los clientes permitieron reducir, en algunos casos, la posibilidad de despedidos. Esto fue posible porque los artistas gráficos respondieron directamente a las exigencias de los clientes. Las relaciones que se desarrollaban en las imprentas daban cierto poder al contratante de los servicios, por ejemplo, algunos clientes solicitaban que su producto fuera elaborado por un empleado puntual. Esta cercanía permitía tener un vínculo entre el cliente y el proceso productivo, intermediado por los trabajadores.

Adicionalmente, en este capítulo se abordan temas como la conformación de zonas de concentración de las artes gráficas. La proximidad física entre unidades de trabajo permitió el fortalecimiento de una red de apoyo entre los trabajadores del sector y permitió una mayor movilidad laboral entre conocidos y excompañeros de trabajo. También se aborda, desde las reflexiones del colectivo de las artes gráficas, la conformación de jerarquías en las empresas. La mayoría de las veces, los roles con mayor "relevancia" debido al volumen de producción, gozaban con una "posición" de mayor importancia respecto a otros roles. En consecuencia, ciertos trabajadores tenían mayor reconocimiento social, pero esto no siempre representó una variación o incremento de salarios frente a sus iguales en el sentido práctico.

En el tercer capítulo se profundiza en las concentraciones espaciales de la industria de las artes gráficas en Bogotá y cómo los cambios en el uso del suelo forzaron a la transformación, no solo el paisaje de la ciudad, sino a su vez, de las diferentes actividades que se desarrollaban en estos espacios. Las artes gráficas sufrieron el desplazamiento y la materialización de la necesidad de encontrar un nuevo espacio para realizar su trabajo; en términos generales, se desplazaron a lugares específicos con el fin de mantener cercanía con sus clientes. Los clientes ya, durante el siglo XX, asociaban ciertas zonas de la ciudad para contratar servicios gráficos.

En relación con la transformación del uso del suelo, se señalan las presiones existentes detrás de intereses privados y públicos en la transformación de estos espacios. Estas presiones empujaron, no solo al traslado de zonas productivas, sino a adoptar modelos 
neoliberales de organización de centros de trabajo. Se señala el caso puntual de la comercialización de bienes y servicios específicos, lo que llevó a la industria, especialmente para pequeños empresarios de las artes gráficas, a adoptar el modelo de los "centros comerciales especializados". Las actuales zonas especializadas en artes gráficas se consolidaron trayendo beneficios, pero también aparecieron otros costos que antes no se contemplaban. La división del espacio se hizo necesaria para el mantenimiento de pequeñas empresas, proceso que al final logró (además de aliviar en parte la carga económica del sostenimiento de un espacio productivo) la construcción de encadenamientos productivos de los diferentes oficios que hacen parte de la industria de artes gráficas.

Con la transformación de la ciudad en los procesos de renovación urbana, el autor muestra cómo se desarrollaron estrategias de impulso económico a esta industria por parte del gobierno local. En el siglo XX se organizaron ferias y otros espacios donde los trabajadores de las artes gráficas podían comercializar mercancías previamente elaboradas; en estos eventos y lugares, las mercancías eran productos que tradicionalmente se consumían en hogares y que eran producidos por la industria de las artes gráficas de forma histórica. Sin embargo, estas estrategias fueron de corta duración y se redujeron a razón de las políticas que privilegiaron el espacio público. Por lo anterior, el autor muestra no solo la transformación de esta actividad económica en la ciudad a raíz de su desplazamiento a otras zonas geográficas, sino que expone cómo el renacer de la misma industria implica un trabajo de posicionamiento político y espacial. Incluso, en este proceso de conformación de sector productivo aparecen otros actores y algunos esfuerzos poco sólidos para esta industria, como lo fue el gobierno de la ciudad.

En el cuarto capítulo se abordan aspectos relacionados con la construcción de la imagen, en doble vía. Primero, describe, desde un proceso histórico a partir del trabajo etnográfico con los trabajadores de las artes gráficas, la importancia que han tenido las piezas gráficas impresas y el papel que juegan en la construcción de la imagen de los trabajadores de las artes gráficas. Inclusive, aborda el sentido de la reputación, la adquisición o transformación de técnicas y recepción de ingresos. Luego, en otro sentido, se enfoca en la perspectiva de los clientes directos que contratan la elaboración de productos visuales. Estos últimos, se relacionan con las imprentas porque buscan un lugar adecuado y, además, establecer un mensaje para sus propios consumidores.

La técnica y el conocimiento que hay detrás de la producción de imágenes, los cambios que se vivieron en los procesos creativos y productivos y, la introducción de tecnología, cambiaron completamente la concepción de calidad entre los trabajadores de las artes gráficas y de los clientes. Por un lado, los trabajadores percibían un deterioro de calidad, comparaban los productos obtenidos con las técnicas digitales introducidas (como mejores) frente a las técnicas análogas anteriores a estas (como peores). Adicionalmente, se muestran los conflictos entre empíricos y profesionales: A. En los aspectos técnicos y estéticos hubo una discusión entre los trabajadores marcada por la experiencia versus el conocimiento formal (educación) y, B. En el aspecto monetario hubo una discusión entre los trabajadores marcada por la competencia y el establecimiento de valor al trabajo realizado. En muchos casos, los precios variaban de acuerdo a las necesidades inmediatas de los trabajadores, lo cual hacía que perdiera valor esta parte de la industria.

Por otro lado, con la llegada de la tecnología digital, la cual se visibilizó sustancialmente con el arribo masivo de las computadoras en los noventa, los clientes comenzaron a tener 
un acercamiento al proceso de elaboración del producto. Con este acceso, la tecnología permitió, a toda clase de personas, tener una aproximación a las herramientas y contenidos del momento. Es interesante, desde un punto de vista económico, observar cómo en algunos sectores los precios podían ser influenciados, no solo por el valor de las materias primas, las mejoras tecnológicas o los volúmenes de producción demandados, sino también por la interacción entre los productores y consumidores (para este caso clientes).

En las imprentas hay una comunicación directa entre clientes y trabajadores, por lo general, esta interacción/relación termina beneficiando al consumidor y no al productor. En el sentido estricto, el margen de ganancia que se persigue con una transacción es indeterminado. Es importante resaltar el análisis del autor, quien muestra detalles de la comunidad y, por este énfasis, puede detectar ciertas fallas de mercado. Es notoria la ausencia de regulación de mercados minoristas: se presta mínima atención a los grandes agregados y no se analizan en las decisiones de política.

Adicionalmente, el cuarto capítulo aborda los efectos de las nuevas relaciones laborales sobre los modelos de producción (benéficas en un sentido económico) y la trasformación tecnológica y estética de las imágenes, bajo la consideración de que hay ciertos conflictos técnicos por la calidad que percibían los trabajadores de las artes gráficas. Productos recurrentes y altamente demandados, con estándares similares y con la misma idea se volvieron una fuente de ingresos recurrente para los trabajadores de las artes gráficas. Así, la nueva tecnología y las nuevas técnicas de imágenes digitales estandarizaron y permitieron producir mayores volúmenes y, optimizar tiempo y recursos en el proceso de elaboración. La innovación e introducción de tecnología fue parte fundamental de la supervivencia y evolución de la industria.

En economía hay ciertos bienes y servicios que no tienen un sustituto perfecto (se tienen algunos complementarios, pero, ciertamente, no pueden ser reemplazados con facilidad), esta puede ser una descripción justa para los productos que por tradición se consumen en las artes gráficas. Aún con la introducción de tecnología, los cambios en las técnicas de diseño y las transiciones en las preferencias de los consumidores, hay productos que prevalecen en la industria de las artes gráficas. Estos productos hacen parte de lo que se podría denominar la canasta de consumo de hogares y empresarios en la actualidad. Éstos permiten sostener parte de una industria que ha tenido que adaptarse y evolucionar con las dinámicas que ha establecido el modelo neoliberal.

Esta biografía colectiva recoge las experiencias y lecciones de una comunidad trabajadora que vivió, en diferentes momentos, transiciones en una actividad económica en la que sus consumidores demandaban innovación constante en los diferentes procesos que la componen. Al ser una industria que es transversal a muchas otras, materializa y vende ideas, conocimiento, productos, entre otros. El corte que tomó la investigación desde la antropología laboral permite conocer a nivel detallado las estructuras sociales, laborales y personales que conviven y fluyen en un sector de la economía. Asimismo, permite conocer la creación de redes de apoyo, la transferencia de conocimiento, el aprendizaje de un oficio sin una formación estrictamente formal, las relaciones de poder que se establecen en los lugares de trabajo, las dinámicas entre los productores y consumidores que lograron involucrar asuntos técnicos y económicos, entre muchos otros aspectos que soportan el flujo de esta actividad. 
Ahora bien, desde la economía, el mercado laboral es una variable de relevancia en la microeconomía y en la macroeconomía. La primera analiza las relaciones de los hogares y las firmas, no solo desde una perspectiva de consumidor, sino como parte de la función de producción (firmas) y la fuerza laboral transforma los factores productivos. A su vez, desde una visión macroeconómica, el mercado laboral hace parte fundamental de los agregados macro que son la base de los modelos con los cuales se toman decisiones en diferentes escalas de la economía nacional, regional o local. El enfoque que desarrolló Velandia Díaz muestra que se puede indagar la complejidad social y no solo los procesos productivos y transaccionales (que para muchos son el principal interés cuando se profundiza en un sector específico de la economía, donde prima el análisis macro en las variables que se analizan).

Conocer a fondo las estructuras del mercado laboral, las historias y contextos, ayuda a interpretar los fenómenos que se perciben. Sobre todo, si consideramos que desde las estadísticas y los modelos, muchos fenómenos no son comprensibles del todo. Tener en cuenta el nivel de agregación, conocer las necesidades, condiciones, transformaciones y demandas de una actividad económica en relación directa con su mano de obra, puede permitir el fortalecimiento de las políticas que se diseñan e implementan en la sociedad.

Finalmente, esta biografía es tanto es una aproximación personal al mercado laboral, resalta historias, que por simples o cotidianas que parezcan, hacen evidentes las "fallas" estructurales que entorpecen el progreso de una actividad en general. Las "fallas de mercado" aparecen indirectamente por la falta de regulación y de garantías mínimas del Estado para con los asalariados e independientes en una actividad. En la exposición de casos puntuales dentro del libro, los trabajadores están expuestos a las injusticias de un mercado monopolizado y que privilegia a grupos selectos y reducidos; por su parte, el Estado resalta los deberes de los particulares, pero solo ocasionalmente recuerda los derechos que tienen.

El autor expone en este libro la transformación de mercados a diferentes escalas, mostrando la importancia que ha tenido y que tiene la industria de las artes gráficas como comunicadora a la sociedad. Explora la construcción de una actividad económica desde quienes la componen y las transiciones veloces que han experimentado a razón del modelo neoliberal. Los cambios, no solo pusieron sobre la mesa nuevos retos de adaptación en modelos productivos, sino que se manifestaron en diferentes ámbitos: la forma en que se concibió el trabajo; la calidad del trabajo; el deterioro de las condiciones de los empleados; la constante incertidumbre por la inestabilidad laboral y; la obsolescencia de técnicas y herramientas. Todo lo cual llevó al incremento de emprendimientos marcados, en muchos casos, por el poco éxito. Los trabajadores gráficos que decidían independizarse no tenían experiencia en las áreas no técnicas de un negocio; esto visibilizó las deficiencias formativas y estancamientos de los trabajadores en roles específicos de la industria. En definitiva, el modelo neoliberal había impuesto unos estándares que para algunas generaciones ya no estaban al alcance.

Este libro expone la relevancia de conocer y profundizar en las transformaciones del trabajo como variable determinante en el proceso evolutivo de las actividades económicas. Desarrolla un análisis desde una etnografía situada, puntualiza hechos históricos, lugares, políticas, entre otros aspectos que, en una lectura encadenada, permiten conocer a fondo la construcción de diferentes alianzas sociales y productivas que están inmersas en la economía. Desde mi punto de vista, muestra una metodología 
valiosa para abordar los sistemas económicos y sus transformaciones; al mismo tiempo, deja en evidencia los impactos de la introducción abrupta de un modelo globalizado en una industria poco desarrollada y competitiva. 